\title{
Optimization of Reflux Conditions for Total Flavonoid and Total Phenolic Extraction and Enhanced Antioxidant Capacity in Pandan (Pandanus amaryllifolius Roxb.) Using Response Surface Methodology
}

\author{
Ali Ghasemzadeh and Hawa Z. E. Jaafar \\ Department of Crop Science, Faculty of Agriculture, University Putra Malaysia, 43400 Serdang, Selangor, Malaysia \\ Correspondence should be addressed to Ali Ghasemzadeh; alighasemzadeh@upm.edu.my
}

Received 11 April 2014; Revised 6 June 2014; Accepted 3 July 2014; Published 23 July 2014

Academic Editor: Fred Stevens

Copyright (C) 2014 A. Ghasemzadeh and H. Z. E. Jaafar. This is an open access article distributed under the Creative Commons Attribution License, which permits unrestricted use, distribution, and reproduction in any medium, provided the original work is properly cited.

\begin{abstract}
Response surface methodology was applied to optimization of the conditions for reflux extraction of Pandan (Pandanus amaryllifolius Roxb.) in order to achieve a high content of total flavonoids (TF), total phenolics (TP), and high antioxidant capacity (AC) in the extracts. Central composite experimental design with three factors and three levels was employed to consider the effects of the operation parameters, including the methanol concentration (MC, $40 \%-80 \%$ ), extraction temperature (ET, $\left.40-70^{\circ} \mathrm{C}\right)$, and liquid-to-solid ratio (LS ratio, $20-40 \mathrm{~mL} / \mathrm{g}$ ) on the properties of the extracts. Response surface plots showed that increasing these operation parameters induced the responses significantly. The TF content and AC could be maximized when the extraction conditions (MC, ET, and LS ratio) were $78.8 \%, 69.5^{\circ} \mathrm{C}$, and $32.4 \mathrm{~mL} / \mathrm{g}$, respectively, whereas the TP content was optimal when these variables were $75.1 \%, 70^{\circ} \mathrm{C}$, and $31.8 \mathrm{~mL} / \mathrm{g}$, respectively. Under these optimum conditions, the experimental TF and TP content and AC were $1.78,6.601 \mathrm{mg} / \mathrm{g}$ DW, and $87.38 \%$, respectively. The optimized model was validated by a comparison of the predicted and experimental values. The experimental values were found to be in agreement with the predicted values, indicating the suitability of the model for optimizing the conditions for the reflux extraction of Pandan.
\end{abstract}

\section{Introduction}

Phytochemicals are important compounds found in medicinal plants that exert positive effects on human health or in amelioration of diseases. Though many phytochemicals have been identified, a great many are yet to be identified [1]. According to a report by the World Health Organization, $80 \%$ of the population in developing countries depends on traditional medicine for primary health care and $85 \%$ of traditional medicine is derived from plant extracts [2]. Extraction and analysis of plant matrices are primary and important processes for the quality control, modernization, and development of herbal formulations [3]. In general, the first step of complete extraction is the selection of plant parts and careful preparation of plant extracts and a thorough review of the existing literature to determine the most suitable protocols for a specific group of phytochemicals or plant species. Traditionally, the extraction of phenolic acids and flavonoid compounds is accomplished by reflux or Soxhlet extraction [4]. However, prolonged extraction at high temperature may degrade flavonoid and phenolic acid compounds [5] and involves a high energy cost. A model for optimizing the most relevant operational parameters is required in order to achieve higher extraction yield. Response surface methodology (RSM) is a collection of statistical and mathematical techniques that is used to optimize the range of variables in various experimental processes with reducing the number of experimental runs, cost, and time compared to other methods $[6,7]$. Pandan (Pandanus amaryllifolius Roxb.) is a tropical plant of the family Pandanaceae. Pandan has narrow and strap-shaped green leaves with a spiral arrangement [8]. Pandan is characterized by a sweet and 
TABLE 1: Independent variables and their coded and actual values used for optimization.

\begin{tabular}{|c|c|c|c|c|c|c|c|}
\hline \multirow{2}{*}{ Independent variable } & \multicolumn{7}{|c|}{ Coded level } \\
\hline & Unit & Symbol & -1 & 0 & +1 & Axial $(-\alpha)$ & Axial $(+\alpha)$ \\
\hline $\mathrm{MC}$ & $\%$ & $X_{1}$ & 10.52 & 50 & 89.48 & 20 & 80 \\
\hline ET & ${ }^{\circ} \mathrm{C}$ & $X_{2}$ & 23.68 & 50 & 76.32 & 30 & 70 \\
\hline LS ratio & $\%$ & $X_{3}$ & 16.84 & 30 & 43.16 & 20 & 40 \\
\hline
\end{tabular}

MC: methanol concentration; ET: extraction temperature; LS ratio: liquid to solid ratio.

TABLE 2: The result of experimental and predicted values of reflux extraction of TF, TP, and AC.

\begin{tabular}{|c|c|c|c|c|c|c|c|c|c|}
\hline \multirow{2}{*}{ Run } & \multirow{2}{*}{$X_{1}$} & \multirow{2}{*}{$X_{2}$} & \multirow{2}{*}{$X_{3}$} & \multicolumn{2}{|c|}{ TF (mg/g DW) } & \multicolumn{2}{|c|}{$\mathrm{TP}(\mathrm{mg} / \mathrm{g} \mathrm{DW})$} & \multicolumn{2}{|c|}{$\mathrm{AC} \%$} \\
\hline & & & & $\begin{array}{c}\text { Experimental } \\
\text { values }\end{array}$ & $\begin{array}{c}\text { Predicted } \\
\text { values }\end{array}$ & $\begin{array}{c}\text { Experimental } \\
\text { values }\end{array}$ & $\begin{array}{c}\text { Predicted } \\
\text { values }\end{array}$ & $\begin{array}{c}\text { Experimental } \\
\text { values }\end{array}$ & $\begin{array}{c}\text { Predicted } \\
\text { values }\end{array}$ \\
\hline 1 & 10.52 & 50 & 30 & 0.55 & 0.56 & 3.12 & 3.18 & 44.70 & 44.80 \\
\hline 2 & 80 & 70 & 20 & 1.52 & 1.50 & 6.24 & 6.20 & 83.20 & 83.37 \\
\hline 3 & 50 & 50 & 16.84 & 1.16 & 1.15 & 5.55 & 5.50 & 70.40 & 70.42 \\
\hline $4(\mathrm{C})$ & 50 & 50 & 30 & 1.33 & 1.26 & 5.94 & 5.90 & 75.80 & 74.48 \\
\hline 5 & 80 & 70 & 40 & 1.74 & 1.70 & 6.58 & 6.55 & 87.50 & 87.36 \\
\hline 6 & 20 & 30 & 20 & 0.67 & 0.68 & 3.79 & 3.82 & 52.00 & 52.19 \\
\hline 7 & 50 & 76.32 & 30 & 1.40 & 1.39 & 6.06 & 6.06 & 80.00 & 80.10 \\
\hline $8(C)$ & 50 & 50 & 30 & 1.22 & 1.26 & 5.84 & 5.90 & 73.00 & 74.48 \\
\hline 9 & 80 & 30 & 40 & 1.44 & 1.43 & 6.10 & 6.16 & 79.40 & 79.81 \\
\hline 10 & 20 & 30 & 40 & 0.71 & 0.71 & 3.82 & 3.85 & 53.10 & 52.98 \\
\hline $11(\mathrm{C})$ & 50 & 50 & 30 & 1.31 & 1.26 & 5.89 & 5.90 & 75.30 & 74.48 \\
\hline 12 & 50 & 50 & 43.16 & 1.35 & 1.33 & 5.95 & 5.91 & 75.80 & 75.60 \\
\hline $13(\mathrm{C})$ & 50 & 50 & 30 & 1.27 & 1.26 & 6.02 & 5.97 & 74.20 & 74.48 \\
\hline 14 & 50 & 23.68 & 30 & 1.15 & 1.17 & 5.89 & 5.83 & 72.70 & 73.10 \\
\hline 15 & 20 & 70 & 20 & 0.81 & 0.79 & 3.99 & 3.93 & 53.80 & 53.43 \\
\hline $16(\mathrm{C})$ & 50 & 50 & 30 & 1.28 & 1.26 & 5.94 & 5.90 & 74.50 & 74.48 \\
\hline 17 & 89.48 & 50 & 30 & 1.38 & 1.40 & 6.11 & 6.14 & 80.50 & 80.61 \\
\hline $18(\mathrm{C})$ & 50 & 50 & 30 & 1.21 & 1.26 & 5.85 & 5.90 & 73.80 & 74.48 \\
\hline 19 & 20 & 70 & 40 & 0.88 & 0.90 & 4.10 & 4.12 & 54.90 & 55.82 \\
\hline 20 & 80 & 30 & 20 & 1.37 & 1.32 & 6.00 & 5.98 & 78.80 & 77.49 \\
\hline
\end{tabular}

(C): central point; $X_{1}$ : MC; $X_{2}$ : ET; $X_{3}$ : LS ratio.

delightful flavor and is widely used as a natural flavor in East Asian countries including Indonesia, Thailand, India, and Malaysia. In Malaysia, Pandan leaves are also used in the production of coconut jam, sweets, desserts, and ice cream. A number of studies have demonstrated that Pandan leaves are a valuable source of phenolic compounds [9-11]. However, far too little attention has been paid to optimization of Pandan extract in folk medicine. To the best of our knowledge, there are no studies and reports undertaken to optimize the flavonoid and phenolic extraction from Pandan leaf, following that improving of antioxidant activity using RSM. The aim of this study is to optimize the extraction conditions of a Malaysian Pandanus amaryllifolius variety to achieve high TF and TP content and thus to enhance the AC based on the use of RSM method with a central composite design (CCD) for optimization of the reflux extraction conditions.

\section{Material and Methods}

2.1. Plant Material. Plant samples ( $P$. amaryllifolius) were collected from the North of Malaysia, Bachok, Kelantan province. The samples were identified by the Malaysian Agriculture Research and Development Institute (MARDI) with voucher specimens of MTP008/1. The leaves were shade dried and were powdered using a mechanical grinder. This powered material was used for further analysis.

2.2. Extraction. The optimization procedure for the extraction process focusing on the $\mathrm{MC}(20-80 \%)$, ET $\left(30-70^{\circ} \mathrm{C}\right)$, and LS ratio $(20-40 \mathrm{~mL} / \mathrm{g})$ was devised based on threefactor central composite design, as summarized in Table 1. Dissolving of different LS ratio in different MC was designed by RSM software (Table 2) with a total of 20 extraction 
running sets. Solutions were refluxed at various temperatures $\left(30-70^{\circ} \mathrm{C}\right)$ for $2 \mathrm{~h}$. After reflux, the solutions were cooled at room temperature and were filtered with a Whatman number 1 filter paper and used for future analysis.

2.3. Determination of Total Flavonoids. After extraction, $1 \mathrm{~mL}$ of extracts was diluted with distilled water $(4 \mathrm{~mL})$. Initially, $\mathrm{NaNO}_{2}$ solution $(5 \%, 0.3 \mathrm{~mL})$ was added to each sample. After 5 min $\mathrm{AlCl}_{3}$ solution (10\%) and at $6 \mathrm{~min} \mathrm{NaOH}(1.0 \mathrm{M}$, $2 \mathrm{~mL}$ ) were added. Absorbance of the solutions was read at $430 \mathrm{~nm}[12]$.

2.4. Determination of Total Phenolic Content. Leaf extracts $(1 \mathrm{~mL})$ were diluted with distilled water $(10 \mathrm{~mL})$, and $1 \mathrm{~mL}$ of Folin-Ciocalteu reagent was then added. Solutions were allowed to stand for $5 \mathrm{~min}$. Sodium carbonate $(2 \mathrm{~mL}, 20 \%)$ was added to the solutions, which were then stored under completely dark conditions at room temperature $\left(25^{\circ} \mathrm{C}\right)$ for $90 \mathrm{~min}$. The absorbance of the mixtures was read at $750 \mathrm{~nm}$ [13].

\subsection{Determination of Antioxidant Capacity}

2.5.1. 1,1-Diphenyl-2-picrylhydrazyl (DPPH) Assay. The free radical scavenging activity of extracts was determined according to the Mensor et al. [14] with some modifications. $\mathrm{DPPH}$ was dissolved in methanol to give final concentration of $2 \mathrm{mM}$. Following that, $1 \mathrm{~mL}$ of DPPH solution was added to different concentration of Pandan extracts $(20,40,60$, 80 , and $100 \mathrm{mg} / \mathrm{mL}$ ). The mixture was shaken gently and incubated at $28^{\circ} \mathrm{C}$ in a dark room for $40 \mathrm{~min}$. For the control, methanol was used as a blank. The absorbance of the samples was read at $517 \mathrm{~nm}$ using spectrophotometer. BHT (butylhydroxytoluene) and $\alpha$-tocopherol were used as positive controls. The scavenging activity was calculated using the following formula:

$\%$ inhibition

$$
=\left[\frac{(\text { absorbance of control }- \text { absorbance of sample })}{\text { absorbance of control }}\right]
$$

$\times 100$.

2.6. Separation and Analysis of Flavonoids by Ultrahigh Performance Liquid Chromatography (UHPLC). The UHPLC system (Agilent, Model 1200) with Agilent C18 (4.6 × $250 \mathrm{~mm}, 5 \mu \mathrm{m}$ ) column was used for flavonoid separation and identification. In this system two mobile phases including $0.03 \mathrm{M}$ orthophosphoric acid (A) and methanol HPLC grade (B) were used. The column temperature, flow rate, and injection volume were adjusted at $35^{\circ} \mathrm{C}, 20 \mu \mathrm{L}$, and $1 \mathrm{~mL} / \mathrm{min}$, respectively. The range of detecting wavelength was between 260 and $360 \mathrm{~nm}$. Gradient elution was performed as follows: 0-10 min 40-100\% B, 10-15 min 100\% B, and 15-20 min 100$40 \% \mathrm{~B}$ and finally washing of the column. To prepare the standard solution all flavonoid and phenolic acid standards were dissolved in HPLC grade methanol. The linear regression equation was calculated with $Y=a X \pm b$, where $X$ was concentration of flavonoid and $Y$ was the peak area of flavonoids obtained from UHPLC [15]. Compounds were tentatively identified by comparison of retention times of standards. All flavonoids and phenolic acids standards were purchased from Sigma-Aldrich (Malaysia).

2.7. Experimental Design. RSM was used to determine the optimal extraction conditions for maximizing the TF $\left(Y_{1}\right)$, TP $\left(Y_{2}\right)$, and the $\mathrm{AC}\left(Y_{3}\right)$. The central composite experimental design with 3 levels and 3 factors was used to examine the extraction variables. Design-Expert software (Version 7.0.0) was used for data analysis, model building, and experimental design. The statistical significance of the model and model variables was determined at the $5 \%$ probability level $(P<$ 0.05).

2.8. Statistical Analysis. The Design-Expert software (Version 7.0.0) was used for data analysis, model building, and experimental design. Analysis of variance and response surface analysis were employed to determine the regression coefficients and statistical significance of the model terms and to fit the mathematical models of the experimental data that aimed to optimize the overall region for both response variables. A model was applied to predict the response variables as given below:

$$
\begin{aligned}
Y= & b_{0}+b_{1} X_{1}+b_{2} X_{2}+b_{3} X_{3}+b_{1}{ }^{2} X_{1}{ }^{2}+b_{2}{ }^{2} X_{2}{ }^{2} \\
& +b_{3}{ }^{2} X_{3}{ }^{2}+b_{1} b_{2} X_{1} X_{2}+b_{1} b_{3} X_{1} X_{3}+b_{2} b_{3} X_{2} X_{3},
\end{aligned}
$$

where $Y$ is the predicted dependent variable, $b_{0}$ is a constant that fixes the response at the central point of the experiment, $b_{1}, b_{2}$, and $b_{3}$ are the regression coefficients for the linear effect terms, $b_{1} b_{2}, b_{1} b_{3}$, and $b_{2} b_{3}$ are the interaction effect terms, and $b_{1}{ }^{2}, b_{2}{ }^{2}$, and $b_{3}{ }^{2}$ are the quadratic effect terms, respectively. The relationship between the independent variables (MC: $X_{1}$; temperature: $X_{2}$, and LS ratio: $X_{3}$ ) and the response variables (TF: $Y_{1}$; TP: $Y_{2}$, and $\mathrm{AC}: Y_{3}$ ) was demonstrated by the response surface plots. Table 1 shows information about extraction temperature, MC, and LS ratio of the 20 experiments.

\section{Result and Discussion}

3.1. Model Fitting, Statistical Significance Analysis, and Response Surface of Reflux Extraction of Total Flavonoid and Phenolics. In this study, extraction temperatures below $80^{\circ} \mathrm{C}$ were used for the extraction to minimize the possibility of degradation of the flavonoid and phenolic compounds, which has been observed to occur with the application of high temperatures $[5,16]$. In addition, the Maillard reaction may occur at high temperatures, resulting in undesired compounds [17]. The results of the experiment and the extraction conditions are shown in Table 2. Significant $(P<$ 0.05 ) regression relationships between the response and independent variables were observed. The TF and TP contents of the extract were more significantly affected by the MC 
TABLE 3: Predicted models and statistical parameters calculated after implementation of three-factor central composite design.

\begin{tabular}{|c|c|c|c|c|c|}
\hline $\begin{array}{l}\text { Measured } \\
\text { parameters }\end{array}$ & Predicted models & $R^{2}$ & $\begin{array}{c}R^{2} \\
\text { (adjusted) } \\
\end{array}$ & $\begin{array}{c}\text { Regression } \\
(P \text { value })\end{array}$ & $\begin{array}{l}\text { Lack of fit } \\
(P \text { value })\end{array}$ \\
\hline $\mathrm{TF}$ & $\begin{array}{l}+1.26+0.36 X_{1}+0.095 X_{2}+0.057 X_{3}+0.018 X_{1} X_{2}+0.023 X_{1} X_{3} \\
+0.023 X_{2} X_{3}-0.16 X_{1}^{2}+0.021 X_{2}^{2}+0.00938 X_{3}^{2}\end{array}$ & 0.98 & 0.97 & 0.0001 & 0.366 \\
\hline $\mathrm{TP}$ & $\begin{array}{l}+5.92+1.15 X_{1}+0.12 X_{2}+0.097 X_{3}+0.030 X_{1} X_{2}+0.038 X_{1} X_{3} \\
+0.040 X_{2} X_{3}-0.76 X_{1}^{2}+0.026 X_{2}^{2}-0.10 X_{3}^{2}\end{array}$ & 0.99 & 0.99 & 0.0001 & 0.295 \\
\hline $\mathrm{DPPH}$ & $\begin{array}{l}+74.46+14.19 X_{1}+2.20 X_{2}+1.20 X_{3}+1.18 X_{1} X_{2}+0.40 X_{1} X_{3} \\
+0.40 X_{2} X_{3}-6.89 X_{1}^{2}+1.05 X_{2}^{2}-0.82 X_{3}^{2}\end{array}$ & 0.99 & 0.99 & 0.0001 & 0.266 \\
\hline
\end{tabular}

$(20-80 \%)$, ET $\left(30-70^{\circ} \mathrm{C}\right)$, and LS ratio $(20-40 \mathrm{~mL} / \mathrm{g})$. High TF and TP contents of 1.74 and $6.58 \mathrm{mg} / \mathrm{g}$ DW, respectively, were observed in the Pandan extracts using treatment run 5 (Table 2). The predicted TF and TP contents for treatment 5 were 1.7 and $6.55 \mathrm{mg} / \mathrm{g} \mathrm{DW}$, which were consistent with the experimental values. The most striking observation from the data is that when the MC $\left(X_{1}\right)$ increased from $20 \%$ to $80 \%$ (at $X_{2}: 30$ and $X_{3}: 40$ ), the TF and TP content increased from 0.71 to $1.44 \mathrm{mg} / \mathrm{g} \mathrm{DW}$ and from 3.82 to $6.10 \mathrm{mg} / \mathrm{g} \mathrm{DW}$, respectively. Increasing the LS ratio resulted in an increment of the TF content of the extracts. In addition, a lower TF content was recorded at lower LS ratio $(20: 1)$. Increasing the LS ratio from 20 to $40 \%$ increased the TF content by $14.4 \%$ (at $X_{1}: 80 \%$ and $X_{2}: 70^{\circ} \mathrm{C}$ ). In the analysis of the TF content, a good coefficient of determination $\left(R^{2}=0.98\right)$ was obtained, where the model explained most of the observed variations (Table 3). Significant $(P<0.05)$ linear and quadratic effects of the ET, MC, and LS ratio on the TF content $\left(Y_{1}\right)$ were observed. The model $P$ value of 0.0001 implies that the model is significant, with only a $0.01 \%$ chance that a "model $P$ value" this large could be due to noise. The lack of fit test for the model describes the variation in the data around the fitted model. If the model does not fit the data well, the lack of fit value will be significant; consequently, proceeding with investigation and optimization of the fitted response surface is likely to give misleading results. The "lack of fit $P$ value" of 0.366 obtained herein implies that the lack of fit is not significant relative to the pure error. However, no interactive effect of the independent variables was observed. The predicted model obtained for TF $\left(Y_{1}\right)$ was as follows:

$$
\begin{aligned}
Y_{1}= & +1.26+0.36 X_{1}+0.095 X_{2}+0.057 X_{3}+0.018 X_{1} X_{2} \\
& +0.023 X_{1} X_{3}+0.023 X_{2} X_{3}-0.16 X_{1}^{2}+0.021 X_{2}^{2} \\
& +0.00938 X_{3}^{2} .
\end{aligned}
$$

The data in Table 2 demonstrate that when the LS ratio increased from $20: 1$ to $40: 1$, the TP content also increased by about $5.4 \%$ (at $X_{1}: 80 \%$ and $X_{2}: 70^{\circ} \mathrm{C}$ ). It is plausible that these results are due to the fact that more solvent could enter the cells while more phenolic compounds could permeate into the solvent at higher LS ratios [18]. The results of previous study showed that as the liquid/solid ratio increased, the content of phenolic compounds in the extract of E. oleracea was enhanced [19]. The highest content of phenolics was reportedly obtained from fruits of E. oleracea at a LS ratio of $40: 1(\mathrm{~mL} / \mathrm{g})$. The results of another study showed that a high total phenolics value was obtained from Parkia speciosa at the LS ratio of $20 \mathrm{~mL} / \mathrm{g}$, whereas the total phenolics content was unaffected by the ET [20]. In current study, the predicted model obtained for TP $\left(Y_{2}\right)$ extraction was as follows:

$$
\begin{aligned}
Y_{2}= & +5.92+1.15 X_{1}+0.12 X_{2}+0.097 X_{3} \\
& +0.030 X_{1} X_{2}+0.038 X_{1} X_{3}+0.040 X_{2} X_{3} \\
& -0.76 X_{1}^{2}+0.026 X_{2}^{2}-0.10 X_{3}^{2}
\end{aligned}
$$

The model $P$ value of 0.0001 implies that the model is significant (Table 3 ). There is only a $0.01 \%$ chance that such as large "model $P$ value" could be due to noise. The "lack of fit $P$ value" of 0.295 implies that the lack of fit is not significant, relative to the pure error. The effect of the variables and the interaction of these variables on the responses can be seen in Figures 1 and 2. Figure 1(a) shows the effect of interaction of the MC and the ET on the TF content of the extract at a fixed LS ratio of $30 \%$. The minimum TF value was obtained at the lowest MC and the maximum TF value was obtained at $80 \%$ methanol at the fixed ET of $70^{\circ} \mathrm{C}$. Figure $1(\mathrm{~b})$ shows the effect of the interaction of $\mathrm{MC}$ and the LS ratio on the TF content at a fixed ET of $50^{\circ} \mathrm{C}$. The minimum TF value was also obtained at the lowest $\mathrm{MC}$ and the maximum TF value was obtained at $80 \%$ methanol at the fixed LS ratio of $40 \%$. Figure 1 (c) shows the effect of interaction of the ET and the LS ratio on the TF content at a fixed MC of 50\%. The minimum TF content was observed at the lowest LS ratio (20\%) and the maximum TF value was obtained at a LS ratio of $40 \%$ using the fixed ET of $70^{\circ} \mathrm{C}$. Moreover, the results indicated that the MC was the most significant factor affecting the responses at the $P<0.01$ level. Figure 2(a) shows the effect of interaction of the MC and the ET on the TP content at a fixed LS ratio of $30 \%$. As shown in Figure 2, the TP content increased significantly to ca. $84.5 \%$ as the MC increased (from 20 to $80 \%$ ). Furthermore, the TP content increased slightly as the LS ratio increased from 20 to $40 \%$ (Figure 2(b)). Figure 2(c) shows the effect of interaction of the ET and the LS ratio on the TP content at $50 \%$ methanol. The TP content increased significantly as the LS ratio increased up to $32 \%$, but beyond a LS ratio of $\sim 32 \%$ the TP content decreased. These findings suggest that the extraction yield of TF and TP was influenced primarily by the $\mathrm{MC}$ rather than the ET. It is difficult to explain this result, but this trend might be related to the increased solubility of the flavonoid compounds in the mixture of methanol and water [21]. The findings of the current study are consistent with 


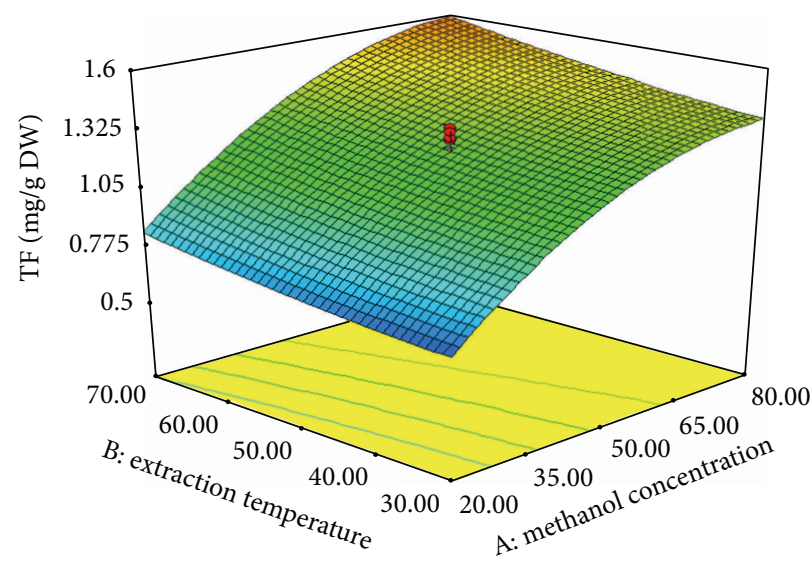

(a)

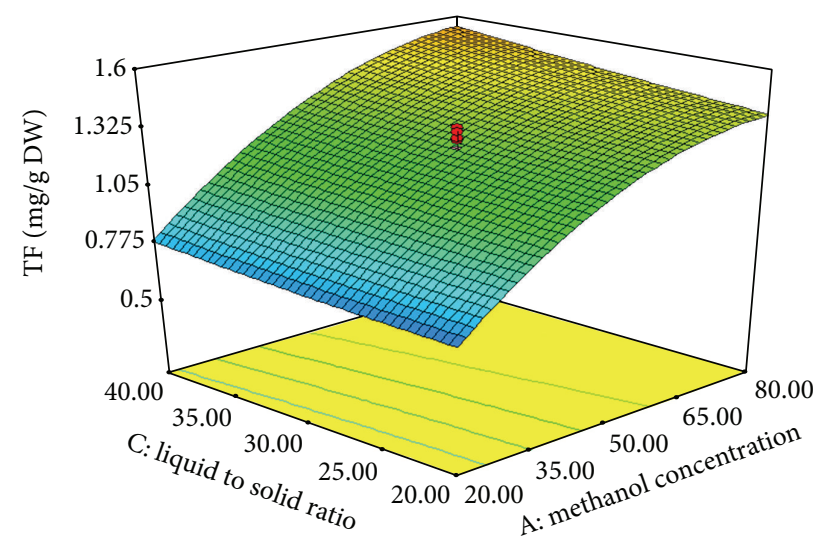

(b)

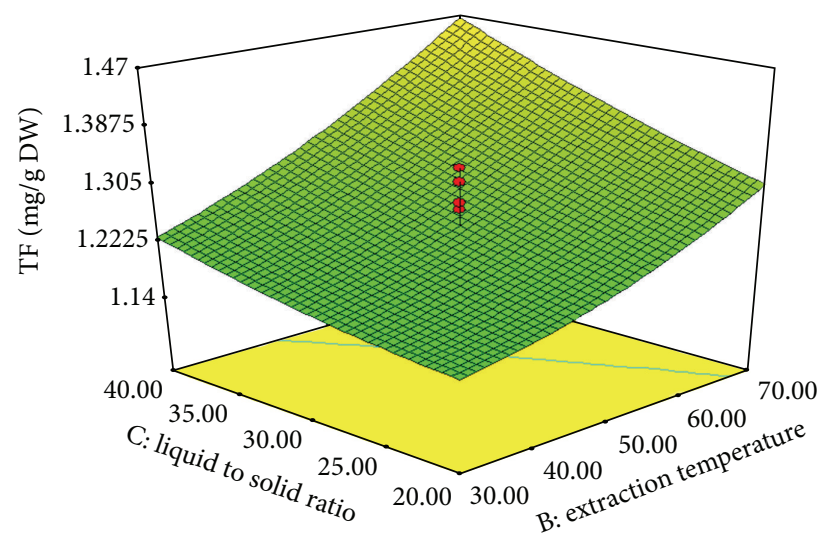

(c)

Figure 1: Response surface plots for the effects of MC (20-80\%), ET (30-70 C), and LS ratio $(20-40 \mathrm{~mL} / \mathrm{g})$ on the TF content of Pandan extract. MC and ET (a), MC and LS ratio (b), and ET and LS ratio (c).

those of Liyana-Pathirana and Shahidi [22], who found that the TF content of wheat increased with increasing ethanol concentration.

The result of our study showed that TF and TP content increased with increasing of the temperature till $70^{\circ} \mathrm{C}$, but we cannot say that this trend will continue even for high temperatures. Previous studies have shown that the application of very high temperatures $\left(\geqslant 95^{\circ} \mathrm{C}\right)$ may alter the concentration and composition of phenolic compounds [23]. Some of the authors reported that critical temperature for flavonoids is below $80^{\circ} \mathrm{C}$ [24]. In different plants and organs this temperature will be variable and according to the previous studies this changes in phenolic acids and flavonoids at high temperature could be related to PAL or CHS enzymes activity at high or low temperature [25]. At high temperature, the flavonoid and phenolic content can be increased as a result of enhancement of their solubility, extraction rate, diffusion rate, and the reduced surface tension and solvent viscosity [26]. However, further increment of the ET may degrade flavonoids and phenolics due to destabilization of the compounds by reaction with other plant components or enzymatic and chemical degradation, thus reducing the extraction efficiency [27]. In contrast with the current results,
Gan and Latiff [20] reported that, in the extraction of Parkia speciosa, the highest phenolic concentration was achieved at an $\mathrm{ET}$ of $35^{\circ} \mathrm{C}$ and the extraction rate could be increased by reducing the extraction time as well as increasing the ET [28].

3.2. Model Fitting, Statistical Significance Analysis, and Response Surface of Reflux Extraction of Antioxidant Capacity $(A C)$. The AC of the extract was significantly affected by the temperature, solvent concentration, and LS ratio $(P<0.05)$ with three linear effects $\left(X_{1}, X_{2}\right.$, and $\left.X_{3}\right)$, two quadratic effects $\left(X_{1}{ }^{2}\right.$ and $\left.X_{2}{ }^{2}\right)$, and three interactive effects $\left(X_{1} X_{2}\right.$, $X_{1} X_{3}$, and $\left.X_{2} X_{3}\right)$. The DPPH capacity of the extract ranged from 44.7 to $87.5 \%$ when treatments 1 and 5 were, respectively, employed. The predicted AC values for treatments 1 and 5 were, respectively, 44.8 and $87.36 \%$, which were close to the experimental values. The effect of the variables and their interaction on the $\mathrm{AC}$ of the Pandan extracts is shown in Figure 3. The AC increased in positive proportion to the $\mathrm{MC}$ in the range of $20-80 \%$ for the extraction medium. Thus, the $\mathrm{MC}$ of the extraction medium had a significant influence on the antioxidant properties of the Pandan extracts. LiyanaPathirana and Shahidi [22] reported that a higher AC was obtained in the extraction of wheat by using $50 \%$ ethanol 


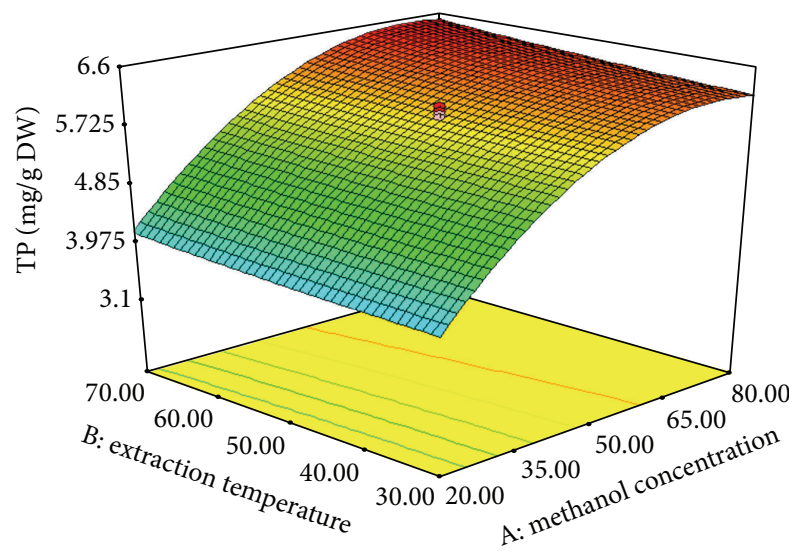

(a)

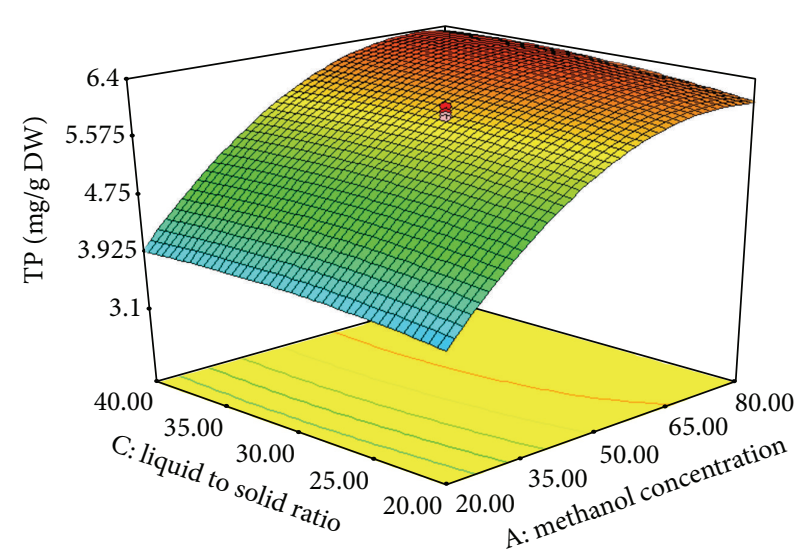

(b)

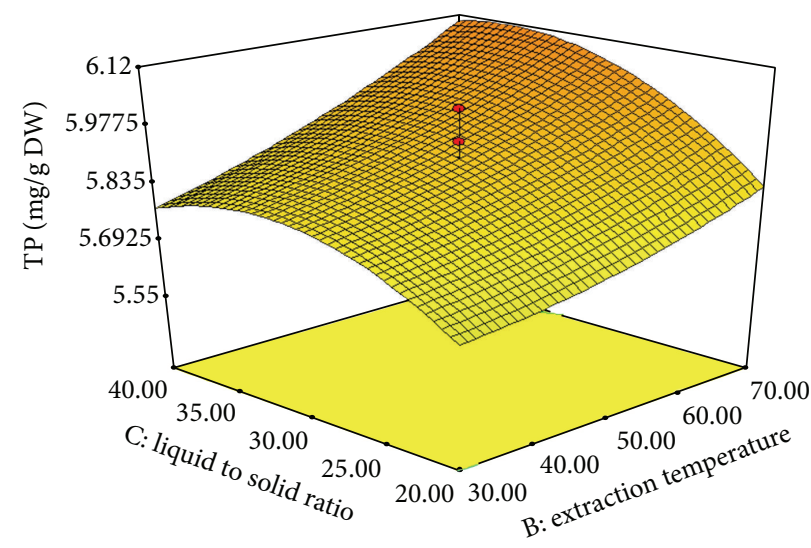

(c)

Figure 2: Response surface plots for the effects of MC (20-80\%), ET $\left(30-70^{\circ} \mathrm{C}\right)$, and LS ratio $(20-40 \mathrm{~mL} / \mathrm{g})$ on the TP content of Pandan extract. MC and ET (a), MC and LS ratio (b), and ET and LS ratio (c).

compared to other aqueous solvents. The current finding is in agreement with those of Pompeu et al. [19] and Kiassos et al. [29], who demonstrated that the concentration of ethanol had a significant influence on the AC of onion extract.

The ET caused a linear increase in the AC of wheat extract, and increasing the temperature increased the total AC. It was confirmed that the rate of extraction of thermally stable antioxidants at elevated temperature was higher than the rate of decomposition of less soluble antioxidants [22]. The temperature utilized during extraction generally influences the compound stability due to chemical and enzymatic degradation and losses by thermal decomposition; these factors have been suggested to be the main mechanisms underlying reduction of the polyphenol content in the extraction of grape [30]. Pompeu et al. [19] obtained high AC in the extraction of Euterpe oleracea at a temperature of $58^{\circ} \mathrm{C}$. Similarly, high $\mathrm{AC}$ of wheat extracts was observed when a temperature of $61^{\circ} \mathrm{C}$ was utilized [22] and high AC was achieved (83.37\%) when the LS ratio was low $(20 \mathrm{~mL} / \mathrm{g})$. The latter is plausibly due to increased probability of the antioxidant components coming into contact with the extraction solvent as the amount of solvent increased. However, further increase of the LS ratio may dilute the extraction solution thereby lowering the
AC. In another study, high AC of Parkia speciosa extract was achieved using a liquid/solid ratio of $20 \mathrm{~mL} / \mathrm{g}$ [20]. The regression equation obtained for the $\mathrm{AC}\left(\mathrm{Y}_{3}\right)$ as the response variable also showed significant $(P<0.05)$ dependence of $Y_{3}$ on the variation of the independent variables. The predicted model obtained for $Y_{3}$ is given below:

$$
\begin{aligned}
Y_{3}= & +74.46+14.19 X_{1}+2.20 X_{2}+1.20 X_{3} \\
& +1.18 X_{1} X_{2}+0.40 X_{1} X_{3}+0.40 X_{2} X_{3} \\
& -6.89 X_{1}^{2}+1.05 X_{2}^{2}-0.82 X_{3}^{2} .
\end{aligned}
$$

The model $P$ value of 0.0001 obtained for the AC implies that the model is significant (Table 3 ). The "lack of fit $P$ value" of 0.266 implies that the lack of fit is not significant, relative to the pure error. There is a $26.65 \%$ chance that a "lack of fit $F$ value" this large could occur due to noise. One question that needs to be asked, however, is why does software take about five or six center points in the design? The reason is also related to the variance of a predicted value. When fitting a response surface we want to estimate the response function in this design region where we are trying to find the optimum. We want the prediction to be reliable throughout the region and especially near the center since we hope the optimum 


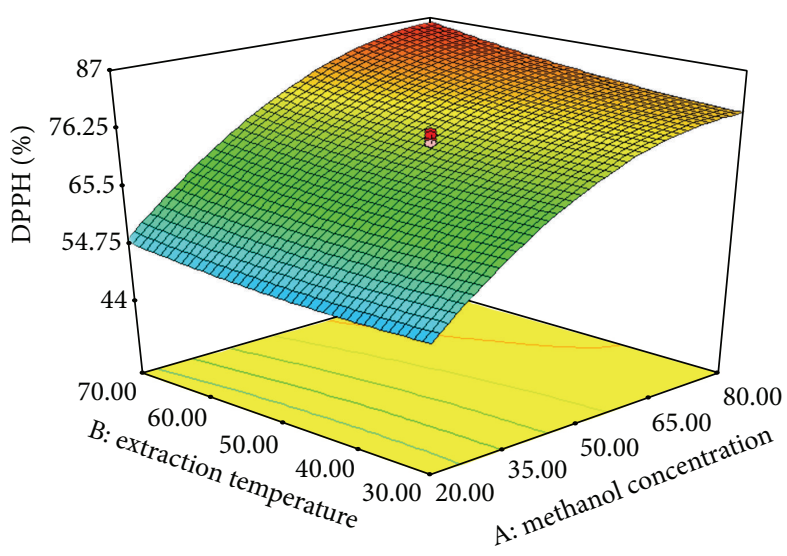

(a)

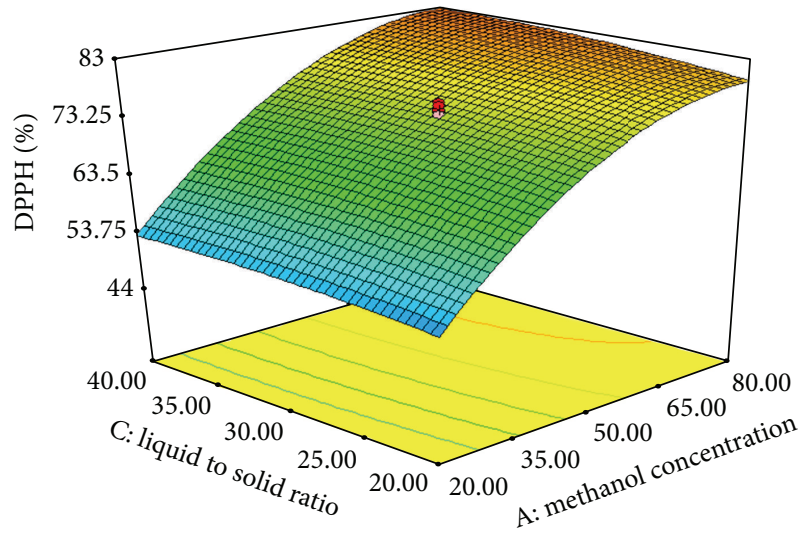

(b)

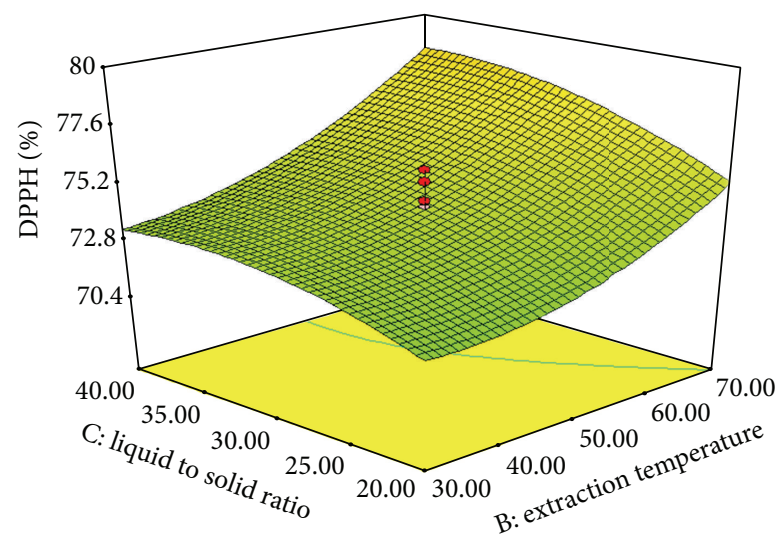

(c)

FIGURE 3: Response surface plots for the effects of MC (20-80\%), ET (30-70 $\left.{ }^{\circ} \mathrm{C}\right)$, and LS ratio $(20-40 \mathrm{~mL} / \mathrm{g})$ on the AC of Pandan extract. MC and ET (a), MC and LS ratio (b), and ET and LS ratio (c).

is in the central region. By picking five to six center points, the variance in the middle is approximately the same as the variance at the edge. If we only had one or two center points, then we would have less precision in the middle than we would have at the edge. As we go farther out beyond a distance of 1 in coded units, we get more variance and less precision. What we are trying to do is to balance the precision at the edge of the design relative to the middle.

3.3. Optimization of Reflux Extraction Condition for TF and TP Content and AC. The optimum reflux extraction conditions for maximizing the TF and TP and for achieving high $\mathrm{AC}$ of Pandan extracts were predicted using the Design-Expert software. Multiple graphical and numerical optimizations were carried out to determine the optimum level of independent variables with desirable response goals. Two optimal conditions were developed for the responses: the $\mathrm{TF}$ content and $\mathrm{AC}$ were maximized using a $\mathrm{MC}$ of $78.8 \%$, ET of $69.5^{\circ} \mathrm{C}$, and LS ratio of $32.4 \mathrm{~mL} / \mathrm{g}$, whereas the corresponding conditions for maximizing TP were $75.1 \%$, $70^{\circ} \mathrm{C}$, and $31.8 \mathrm{~mL} / \mathrm{g}$, respectively (Table 4 , Figure 4 ).

3.4. Verification of the Models. The experiment was performed using the recommended optimum treatment conditions for the three responses to evaluate the adequacy of the response surface models for predicting the optimum response values. As shown in Table 4, the observed values of the TF and TP content and AC were 1.78, $6.601 \mathrm{mg} / \mathrm{g} \mathrm{DW}$, and $87.38 \%$, respectively. The response surface models of TF, TP, and antioxidant activity were verified using the experimental and predicted values. The obtained results from verification experiment were in consent with the predicted values, because nonsignificant $(P>0.05)$ difference was observed between the verification experimental and the predicted values $\left(E_{\mathrm{TF}, \mathrm{TP}}=0.069 \%\right.$; $\left.E_{\mathrm{DPPH}}=0.48 \%\right)$.

3.5. Identification of Flavonoids and Phenolic Acids. Figure 5 shows the UHPLC chromatogram of the identified flavonoid and phenolic acids of the Pandan extract. Gallic acid, (+)catechin, caffeic acid, myricetin, luteolin, and quercetin were identified in the Pandan extract at concentrations of 0.489 , $0.594,0.856,0.076,0.08$ and $0.112 \mathrm{mg} / \mathrm{g} \mathrm{DW}$, respectively. Caffeic acid was the most abundant compound of the identified compounds, and the concentration of phenolic acids was higher than that of the flavonoid compounds in the Pandan extract. 


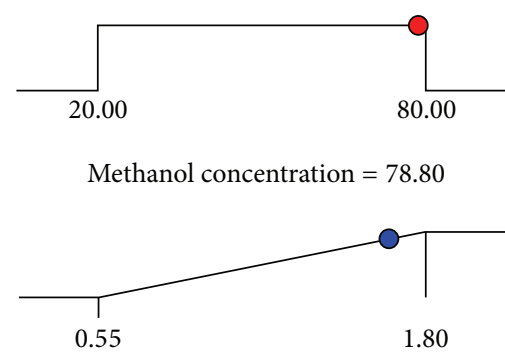

$\mathrm{TF}=1.78125$

Desirability $=0.949$

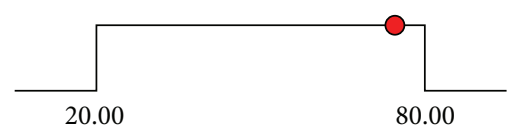

Methanol concentration $=75.10$

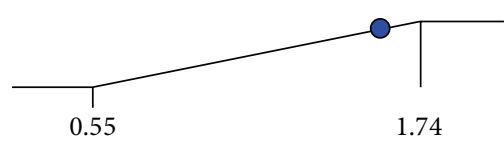

$\mathrm{TF}=1.59726$
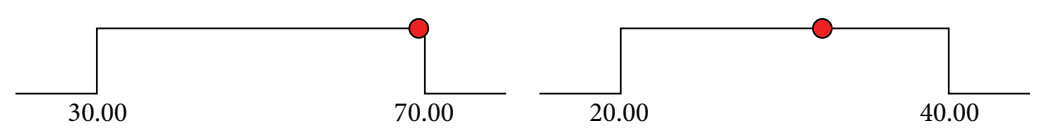

Extraction temperature $=69.50$

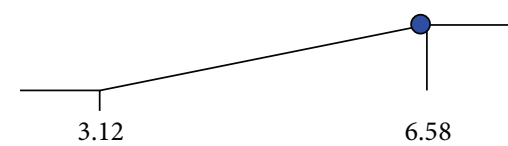

$\mathrm{TP}=6.52991$

Liquid to solid ratio $=32.40$

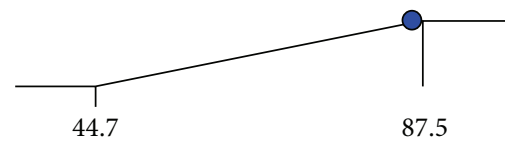

$\mathrm{DPPH}=87.38$

(a)
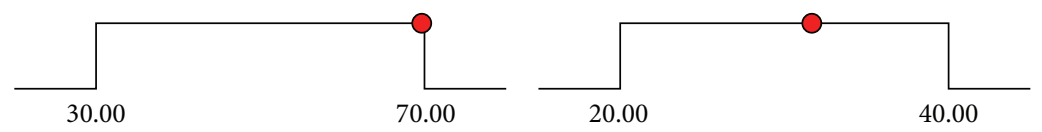

Extraction temperature $=70.00$
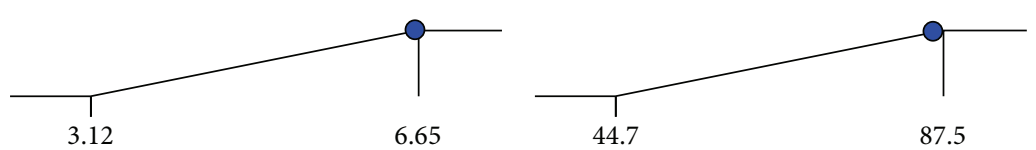

$\mathrm{TP}=6.6010$

$\mathrm{DPPH}=86.0711$

Desirability $=0.943$

(b)

FIgure 4: Predicted value of TF, TP, and DPPH activity of Pandan leaf from optimized extraction condition using RSM ((a) optimized condition for TF and DPPH activity; (b) optimized condition for TP).

TABLE 4: Optimum conditions and experimental value of responses at the optimum conditions.

\begin{tabular}{|c|c|c|c|c|c|c|}
\hline & $\begin{array}{l}\text { Optimum conditions } \\
\text { (predicted) }\end{array}$ & TF content & $\begin{array}{l}\text { Optimum conditions } \\
\text { (predicted) }\end{array}$ & TP content & $\begin{array}{l}\text { Optimum conditions } \\
\text { (predicted) }\end{array}$ & $\mathrm{AC}$ (DPPH assay) \\
\hline $\mathrm{MC}(\%)$ & 78.8 & \multirow{3}{*}{1.78} & 75.1 & \multirow{3}{*}{6.601} & 78.8 & \multirow{3}{*}{87.38} \\
\hline $\mathrm{ET}\left({ }^{\circ} \mathrm{C}\right)$ & 69.5 & & 70 & & 69.5 & \\
\hline LS ratio $(\mathrm{mL} / \mathrm{g})$ & 32.4 & & 31.8 & & 32.4 & \\
\hline
\end{tabular}

TF and TP: mg/g DW; AC: \%.

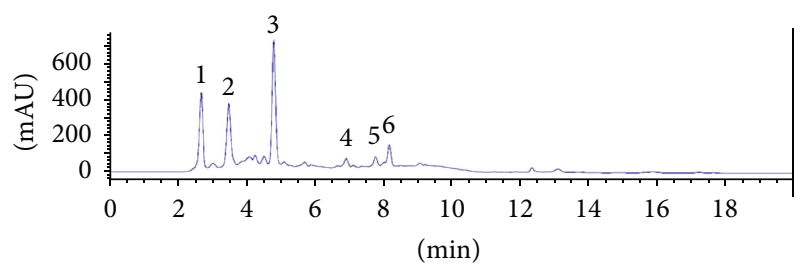

Figure 5: UHPLC chromatogram of Pandan extract. Identified compounds are gallic acid (1), catechin (2), caffeic acid (3), myricetin (4), luteolin (5), and quercetin (6).

\section{Conclusion}

The reflux extraction of TF and TP and the AC of Pandan extract were successfully optimized using RSM. The results indicate that the MC, ET, and LS ratio had a significant effect on the TF and TP extraction yields with consequent enhancement of the $\mathrm{AC}$ of the extracts. The results can be easily explained on the basis that both the ET and the MC have a positive effect on the solubility of flavonoids in the extraction solution. The most efficient set of reflux conditions for Pandan leaf extraction are at MC $78.8 \%\left(X_{1}\right)$, ET $69.5^{\circ} \mathrm{C}$ $\left(X_{2}\right)$, and LS ratio of $32.4 \mathrm{~mL} / \mathrm{g}\left(X_{3}\right)$ for maximizing the TF content and $\mathrm{AC}$ and $75.1 \%\left(X_{1}\right), 70^{\circ} \mathrm{C}\left(X_{2}\right)$, and $31.8 \mathrm{~mL} / \mathrm{g}$ $\left(X_{3}\right)$ for maximizing the TP content with consequently high AC. Moreover, the models used to fit the response variables were significant $(P<0.01)$, and the "lack of fit" was not significant $(P>0.05)$ for all responses, indicating that the models used to fit the response variables were adequate for representing the relationship between the response values and the independent variables.

\section{Conflict of Interests}

The authors declare that they have no conflict of interests regarding the publication of this paper. 


\section{Acknowledgments}

The authors would like to thank the Ministry of Higher Education, Malaysia, and the Research Management Centre, University Putra Malaysia (UPM), for sponsoring this work. Authors also are grateful to the Malaysian Agriculture Research and Development Institute for collecting of the plant samples. The authors would like to acknowledge all staff of Laboratory of Nutrition, Department of Nutrition and Dietetics, Faculty of Medicine and Health Sciences, for all the help and guidance in order to accomplish this project.

\section{References}

[1] J. Boyer and R. H. Liu, "Apple phytochemicals and their health benefits," Nutrition Journal, vol. 3, article 1, 2004.

[2] WHO Organization, WHO Traditional Medicine Strategy 20022005, WHO, 2002.

[3] M. J. Bak, S. Ok, M. Jun, and W. S. Jeong, "6-shogaol-rich extract from ginger up-regulates the antioxidant defense systems in cells and mice," Molecules, vol. 17, no. 7, pp. 8037-8055, 2012.

[4] A. Khoddami, M. A. Wilkes, and T. H. Roberts, “Techniques for analysis of plant phenolic compounds," Molecules, vol. 18, no. 2, pp. 2328-2375, 2013.

[5] A. M. Nuutila, K. Kammiovirta, and K.-M. Oksman-Caldentey, "Comparison of methods for the hydrolysis of flavonoids and phenolic acids from onion and spinach for HPLC analysis," Food Chemistry, vol. 76, no. 4, pp. 519-525, 2002.

[6] F. Gu, F. Xu, L. Tan, H. Wu, Z. Chu, and Q. Wang, “Optimization of enzymatic process for vanillin extraction using response surface methodology," Molecules, vol. 17, no. 8, pp. 8753-8761, 2012.

[7] C. H. Kuo, F. W. Hsiao, J. H. Chen, C. W. Hsieh, Y. C. Liu, and C. J. Shieh, "Kinetic aspects of ultrasound-accelerated lipase catalyzed acetylation and optimal synthesis of 4 '-acetoxyresveratrol," Ultrasonics Sonochemistry, vol. 20, no. 1, pp. 546-552, 2013.

[8] K. V. Peter, Handbook of Herbs and Spices, Elsevier, 2012.

[9] S. R. Chilakwad, K. Manjunath, K. S. Akki, R. Savadi, and N. Deshpande, "Pharmacognostic and Phytochemical investigation of leaves of Pandanus odoratissimus Linn.f.," Ancient Science of Life, vol. 28, no. 2, pp. 3-6, 2008.

[10] A. Ghasemzadeh and H. Z. Jaafar, "Profiling of phenolic compounds and their antioxidant and anticancer activity in pandan (Pandanus amaryllifolius Roxb.) extracts from different locations of Malaysia," BMC Complementary and Alternative Medicine, vol. 13, article 341, 2013.

[11] K. H. Miean and S. Mohamed, "Flavonoid (myricetin, quercetin, kaempferol, luteolin, and apigenin) content of edible tropical plants," Journal of Agricultural and Food Chemistry, vol. 49, no. 6, pp. 3106-3112, 2001.

[12] B. Sultana, F. Anwar, and M. Ashraf, "Effect of extraction solvent/technique on the antioxidant activity of selected medicinal plant extracts," Molecules, vol. 14, no. 6, pp. 2167-2180, 2009.

[13] D.-O. Kim, O. I. Padilla-Zakour, and P. D. Griffiths, "Flavonoids and antioxidant capacity of various cabbage genotypes at juvenile stage," Journal of Food Science, vol. 69, no. 9, pp. C685C689, 2004.

[14] L. L. Mensor, F. S. Menezes, G. G. Leitão et al., "Screening of Brazilian plant extracts for antioxidant activity by the use of
DPPH free radical method," Phytotherapy Research, vol. 15, pp. 127-130, 2001.

[15] H. Bae, G. K. Jayaprakasha, J. Jifon, and B. S. Patil, "Extraction efficiency and validation of an HPLC method for flavonoid analysis in peppers," Food Chemistry, vol. 130, no. 3, pp. 751-758, 2012.

[16] Í. Şensoy, R. T. Rosen, C.-T. Ho, and M. V. Karwe, "Effect of processing on buckwheat phenolics and antioxidant activity," Food Chemistry, vol. 99, no. 2, pp. 388-393, 2006.

[17] J. Shi, M. L. Maguer, Y. Kakuda, A. Liptay, and F. Niekamp, "Lycopene degradation and isomerization in tomato dehydration," Food Research International, vol. 32, no. 1, pp. 15-21, 1999.

[18] K. N. Prasad, E. Yang, C. Yi, M. Zhao, and Y. Jiang, "Effects of high pressure extraction on the extraction yield, total phenolic content and antioxidant activity of longan fruit pericarp," Innovative Food Science \& Emerging Technologies, vol. 10, no. 2, pp. 155-159, 2009.

[19] D. R. Pompeu, E. M. Silva, and H. Rogez, "Optimisation of the solvent extraction of phenolic antioxidants from fruits of Euterpe oleracea using Response Surface Methodology," Bioresource Technology, vol. 100, no. 23, pp. 6076-6082, 2009.

[20] C. Gan and A. A. Latiff, "Optimisation of the solvent extraction of bioactive compounds from Parkia speciosa pod using response surface methodology," Food Chemistry, vol. 124, no. 3, pp. 1277-1283, 2011.

[21] G. K. Jayaprakasha, B. Girennavar, and B. S. Patil, "Radical scavenging activities of Rio Red grapefruits and Sour orange fruit extracts in different in vitro model systems," Bioresource Technology, vol. 99, no. 10, pp. 4484-4494, 2008.

[22] C. Liyana-Pathirana and F. Shahidi, "Optimization of extraction of phenolic compounds from wheat using response surface methodology," Food Chemistry, vol. 93, no. 1, pp. 47-56, 2005.

[23] M. Igual, E. García-Martínez, M. M. Camacho, and N. Martínez-Navarrete, "Effect of thermal treatment and storage on the stability of organic acids and the functional value of grapefruit juice," Food Chemistry, vol. 118, no. 2, pp. 291-299, 2010.

[24] G. Xu, X. Ye, J. Chen, and D. Liu, "Effect of heat treatment on the phenolic compounds and antioxidant capacity of citrus peel extract," Journal of Agricultural and Food Chemistry, vol. 55, no. 2, pp. 330-335, 2007.

[25] M. T. Lafuente, A. R. Ballester, J. Calejero, and L. GonzálezCandelas, "Effect of high-temperature-conditioning treatments on quality, flavonoid composition and vitamin $\mathrm{C}$ of cold stored "Fortune" mandarins," Food Chemistry, vol. 128, no. 4, pp. 10801086, 2011.

[26] Z. Y. Ju and L. R. Howard, "Effects of solvent and temperature on pressurized liquid extraction of anthocyanins and total phenolics from dried red grape skin," Journal of Agricultural and Food Chemistry, vol. 51, no. 18, pp. 5207-5213, 2003.

[27] N. E. Durling, O. J. Catchpole, J. B. Grey et al., "Extraction of phenolics and essential oil from dried sage (Salvia officinalis) using ethanol-water mixtures," Food Chemistry, vol. 101, no. 4, pp. 1417-1424, 2007.

[28] J. E. Cacace and G. Mazza, "Extraction of anthocyanins and other phenolics from black currants with sulfured water," Journal of Agricultural and Food Chemistry, vol. 50, no. 21, pp. 5939-5946, 2002.

[29] E. Kiassos, S. Mylonaki, D. P. Makris, and P. Kefalas, "Implementation of response surface methodology to optimise extraction of onion (Allium cepa) solid waste phenolics," Innovative 
Food Science and Emerging Technologies, vol. 10, no. 2, pp. 246252, 2009.

[30] M. Corrales, S. Toepfl, P. Butz, D. Knorr, and B. Tauscher, "Extraction of anthocyanins from grape by-products assisted by ultrasonics, high hydrostatic pressure or pulsed electric fields: a comparison," Innovative Food Science \& Emerging Technologies, vol. 9, no. 1, pp. 85-91, 2008. 

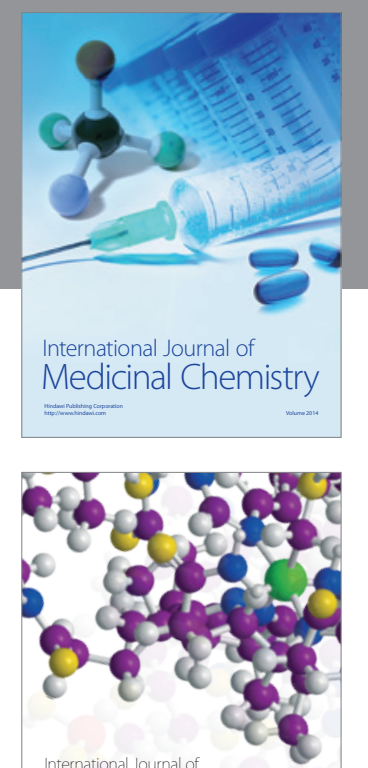

\section{Carbohydrate} Chemistry

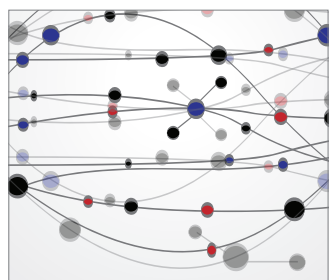

The Scientific World Journal
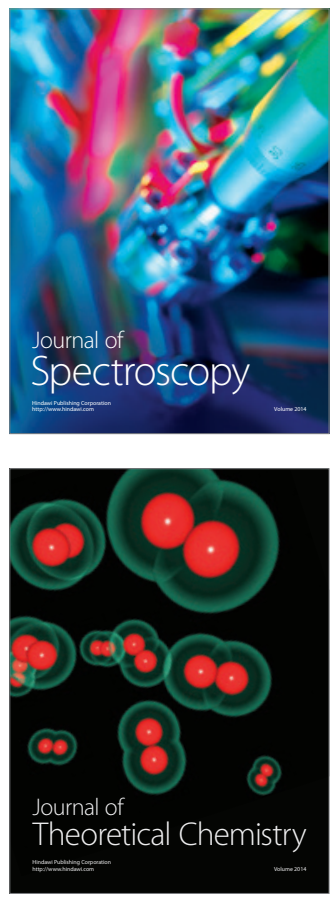
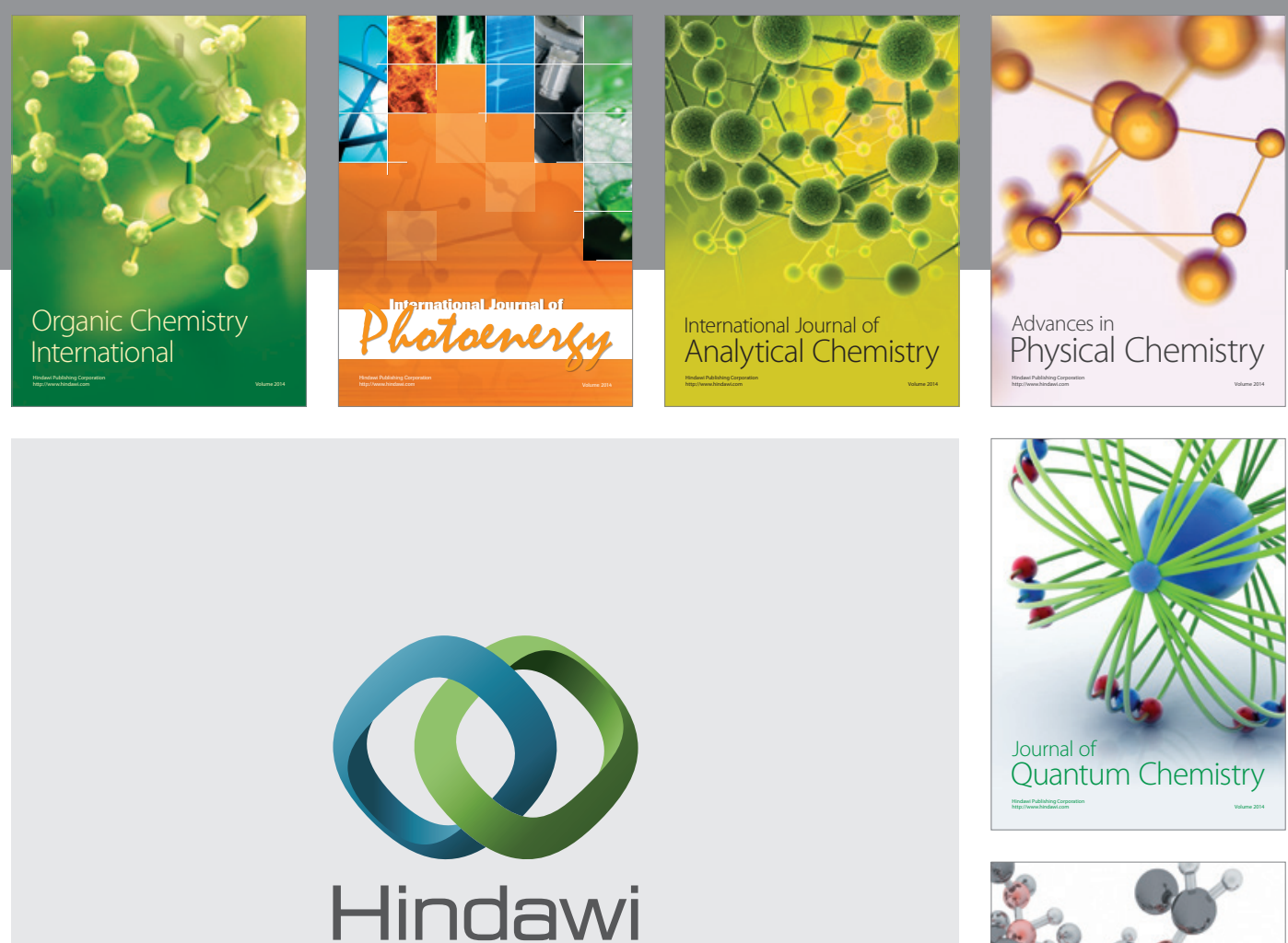

Submit your manuscripts at

http://www.hindawi.com

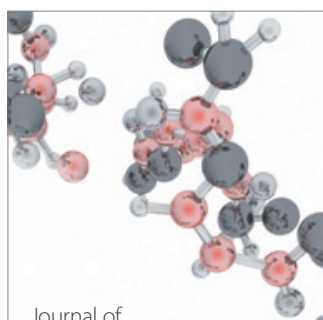

Analytical Methods

in Chemistry

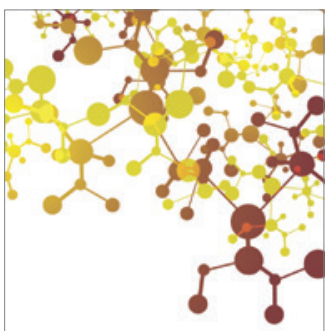

Journal of

Applied Chemistry

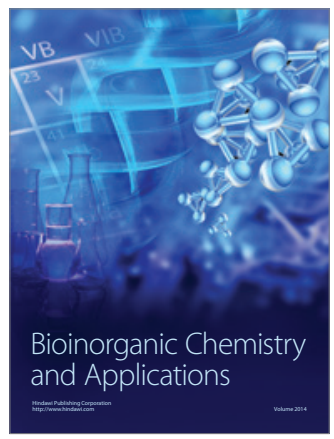

Inorganic Chemistry
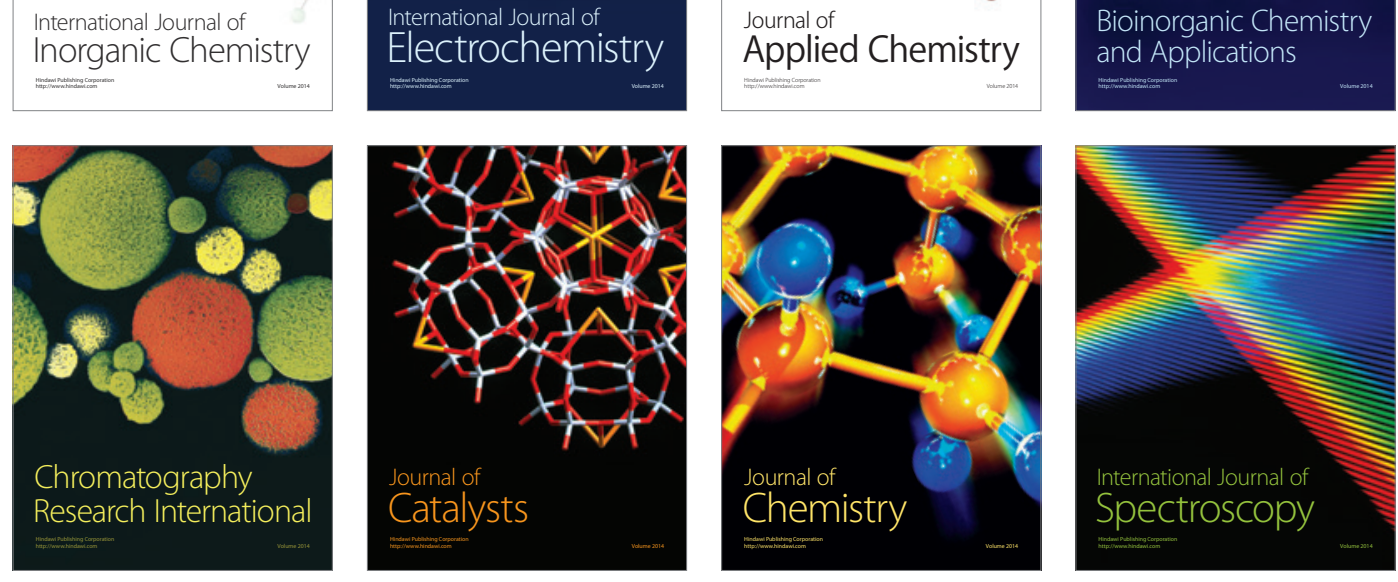